\title{
Sualtı Haberleşmede Çok Yolluluğun Bant Genişliği, Kapasite ve İletim Gücü Üzerindeki Etkisi
}

\author{
Mehmet Ali Çavuşlu ${ }^{1 *}$, Mehmet Ali Altuncu², Hikmetcan Özcan ${ }^{3}$, \\ Fidan Kaya Gülağız ${ }^{4}$, Suhap Şahin ${ }^{5}$
}

Geliş / Received: 15/03/2020

Revize / Revised: 08/06/2020

Kabul / Accepted: 09/06/2020

\section{ÖZ}

Sualtı ortamına yönelik haberleşme teknolojilerindeki gelişmeler, yeni sualtı akustik iletişim tekniklerinin ortaya çıkmasını sağlamıştır. Bu gelişmelere paralel olarak malzeme ve algılayıcı teknolojilerinin de gelişmeleri ile birlikte, bu teknolojiler uygulanabilir hale gelmiştir. Böylece sualtı ortamında yüksek bant genişliklerinde, uzak mesafelere veri iletimine yönelik çalışmalar artmıştır. Sualtı ortamının kaotik yapısı, kaynaktan alıcıya veri iletimini zor hale getirmektedir. Sualtında yüksek frekanslarda uzak mesafelere iletim gerçekleştirilememesi ve yüksek frekanslarda çalışacak şekilde tasarlanan sistemlerin sınırlı bant genişliğine sahip olması nedeni ile sualtı haberleşmeye yönelik çalışmalarda düşük frekanslar tercih edilmektedir. İki nokta arasında gerçekleştirilecek iletişim bant genişliğinden, kaynak iletim gücünden ve kaynak-alıcı arası mesafeden doğrudan etkilemektedir. İletişimin gerçekleştirileceği ortamda kaynaktan yayılan sinyaller algılayıcıda çok yollu olarak alınmaktadır. Özellikle yüzeyden ve dipten yansımalar, algılayıcıda alınan sinyallerin bozulmasına sebep olmaktadır. Bu çalışma kapsamında, sualtı ortamında literatürde önerilen iletim kaybı, emilim kaybı ve ortam gürültüsü modelleri kullanılarak bant genişliği, kapasite ve iletim gücü hesapları gerçekleştirilmiştir. Hesaplamalarda kaynaktan alıcıya ulaşan farklı sayıda çok yollu sinyaller, çok yollu sinyallerin maruz kaldığı farklı dip/yüzey yansıma zayıflamalarının ve kaynak alıcı arası mesafenin bant genişliği, kapasite ve iletim gücü üzerindeki etkisi analiz edilmiştir. Analizler sonucunda kaynaktan alıcıya ulaşan çok yollu sinyallerin sayısının, dip/yüzey yansıma zayıflamalarının seviyesinin ve kaynak alıcı arasındaki mesafenin bant genişliği, kapasite ve iletim gücünü doğrudan etkilediği görülmüştür.

Anahtar Kelimeler-Sualtı akustiği, Bant genişliği, Kanal kapasitesi, İletim gücü

\footnotetext{
1*Sorumlu yazar iletişim: alicavuslu@gmail.com (https://orcid.org/0000-0002-8736-3845) Bilgisayar Mühendisliği Bölümü, Kocaeli Üniversitesi, Umuttepe, Kocaeli, Türkiye 2̇̇letișim: mehmetali.altuncu@kocaeli.edu.tr (https://orcid.org/0000-0002-2948-3937) Bilgisayar Mühendisliği Bölümü, Kocaeli Üniversitesi, Umuttepe, Kocaeli, Türkiye 3iletişim: hikmetcan.ozcan@kocaeli.edu.tr (https://orcid.org/0000-0002-7146-203X) Bilgisayar Mühendisliği Bölümü, Kocaeli Üniversitesi, Umuttepe, Kocaeli, Türkiye 4Illetişim: fidan.kaya@kocaeli.edu.tr (https://orcid.org/0000-0003-3519-9278) Bilgisayar Mühendisliği Bölümü, Kocaeli Üniversitesi, Umuttepe, Kocaeli, Türkiye 5İletişim: suhapsahin@kocaeli.edu.tr (https://orcid.org/0000-0003-1340-8972) Bilgisayar Mühendisliği Bölümü, Kocaeli Üniversitesi, Umuttepe, Kocaeli, Türkiye
} 


\title{
The Effect of Multipath on Bandwidth, Capacity and Transmission Power in Underwater Communication
}

\begin{abstract}
Advances in communication technologies for the underwater environment have led to the emergence of new underwater acoustic communication techniques. In parallel with these developments, with the development of material and sensor technologies, these technologies have become feasible. Thus, the studies for transmitting data at high bandwidths and long distances in the underwater environment have increased. The chaotic nature of the underwater environment makes it difficult to transmit data from the source to the receiver. Low frequencies are preferred in underwater communication studies because the systems designed to operate at high frequencies cannot be transmitted to long distances at high frequencies and have limited bandwidth. Communication between two points directly affects bandwidth, source transmission power, and source-receiver distance. In the environment where the communication will be carried out, the signals emitted from the source are received as multi-way in the sensor. Especially reflections from the surface and bottom cause the signals received in the sensor to be distorted. In this study, using the transmission loss, absorption loss, and ambient noise models proposed in the literature in the underwater environment, bandwidth, capacity, and transmission power calculations were performed. In calculations, the effects of the different number of multipath signals reaching the receiver from the source, the different dip/surface reflection attenuation to which the multipath signals are exposed, and the distance between the source-receiver on the bandwidth, capacity, and transmission power were analyzed. As a result of the analysis, it was found that the number of multipath signals reaching the receiver from the source, the level of the bottom/surface reflection attenuation, and the distance between the source-receiver directly affect the bandwidth, capacity and transmission power.
\end{abstract}

Keywords- Underwater Acoustics, Bandwidth, Capacity, Transmission Power 


\section{GİRIŞ}

Son zamanlarda akustik haberleşme teknolojisinde meydana gelen gelişmeler sualtı ağların geliştirilmesine yönelik deneysel ve araştırmaların artmasını sağlamıştır. Gerçekleştirilen bu çalışmaların sonucu olarak yüksek hızlı sualtı akustik iletişim teknikleri kullanımının artması ve sualtı ortamında çalışacak algılayıcı teknolojisindeki gelişmeler [1] ile noktadan noktaya iletişim bağlantılarının özerk sualtı ağlarına entegrasyonuna yönelik çalışmalar hız kazanmıştır [2].

Sualtı akustik ortamda oluşan kanallar, sualtı ortamının kaotik yapısı nedeni ile günümüzde kullanılan en zor iletişim ortamlarından biri olarak kabul edilmektedir. Sualtı ortamında akustik yayılım en iyi düşük frekanslarda gerçekleşmektedir ve iletişim için kullanılabilir mevcut bant genişliği son derece sınırlıdır. Örneğin, $11 \mathrm{KHz}$ ila $14 \mathrm{KHz}$ arasındaki bir frekans aralığında çalışan akustik sistemde iletişim için gerekli toplam bant genişliği karasal kablosuz sistemlere göre düşük olmasına rağmen $(3 \mathrm{KHz})$, sistem sualtı ortamı için geniş bantlı olarak kabul edilmektedir. Bu nedenle sualtı akustik sistemlerde tanımlı bant genişliğinin merkez frekansa göre ihmal edilememektedir [2].

Sualtı akustik kanalları, kablosuz ağların tasarımını etkileyen çok fazla kısıta sebep olmaktadır. Bu kanallar, karasal bir radyo sisteminden çok daha belirgin bir şekilde, sinyal frekansı ve iletim mesafesine bağlı yol kaybı ile karakterize edilebilirler. Bu nedenle sadece iletim gücü değil, kullanışlı bant genişliği de iletim mesafesine bağlı olarak değişmektedir.

Kapasite, belirli bir güce sahip kaynak ile belirli bir mesafedeki alıcı arasında desteklenebilecek (kuramsal olarak) maksimum veri hızını belirler. Uygulamada, fiziksel olarak kullanılan mekanizmalardan kaynaklanan bant genişliği sınırlamaları ile kaynak spektrumu üzerinde ek kısıtlamalar uygulanır [3]. Sinyal frekansı, akustik enerjinin ısıya aktarılması nedeniyle oluşan emilim kaybını belirler. Bu gerçek, akustik bant genişliğinin iletişim mesafesine bağlılığın ifade eder. Sonuçta ortaya çıkan bant genişliği sınırlaması, akustik yayılım fiziği tarafından belirlendiği gibi, dönüştürücü (transdüser) cihazlarının kısıtlamaları ile belirlenemeyen temel bir sınırlamadır. Emilim kaybı, frekansla ve mesafeyle birlikte artar, sonuçta sonlu iletim gücünün pratik kısıtlamaları dâhilinde mevcut bant genişliğine bir sınır getirir. Sonuç olarak, daha kısa bir iletişim bağlantısı, bir sualtı akustik sistemindeki daha geniş bir bant genişliğini sağlar.

Bu çalışmada, literatürde sunulan sualtı akustik modelleri kullanılarak bant genişliği, kapasite ve iletim gücü hesaplamaları gerçekleştirilmiştir. Bu hesaplamalar sonucu yapılan analizlerde yayılım kaybı olarak silindirik, küresel ve pratik yayılım modelleri kullanılmıştır. Elde edilen sonuçlar ile sualtı ortamında farklı iletim kaybı yaklaşımlarında bant genişliği, kapasite ve iletim kaybı hesaplarının gerçekleştirilebileceği gösterilmiştir.

Makalenin organizasyonu şu şekildedir: Bölüm 2'de sualtı akustiği hakkında temel bilgiler, sualtı ortamının modellenmesi ve sualtı ortamında meydana gelen kayıplar hakkında bilgiler verilmiştir. Bölüm 3 'te literatürde sunulan genel yaklaşımlar kullanılarak bant genişliği, kapasite ve iletim gücü model parametrelerine yönelik gerçekleştirilen hesaplar anlatılmıştır. Bölüm 4'te gerçekleştirilen analizlerin bilime ve günümüz teknolojisine sağlayabileceği katkılar tartışılmıştır.

\section{SUALTI AKUSTIK ORTAMI VE MODELLENMESİ}

Sualtı akustik sinyalleri, bir cismin (gemi pervanesi ve motoru, gemideki metal cisimler, deniz canlıları, dalgalar, vb.) hareketinin (titreşim, çarpma, vb.) oluşturduğu işitilebilen frekans bandında veya dışında ses dalgalarıdır. Ses dalgaları, oluşturdukları basınçla su moleküllerini hareket ettirerek sualtında çok uzak mesafelere kadar yayılırlar [4].

Sualtı ortamında en önemli akustik değişken ses hızıdır ve ses hızının sualtı ortamındaki dağılımı diğer tüm akustik olayları etkiler. Deniz yüzeyinin durumu ile deniz tabanının yapısının bilinmesi, ses hızının davranışına yönelik sınır koşullarının belirlenmesi için önemlidir. Bunlara ek olarak batimetrik özellikler sesin yayılmasını engelleyebilir. Sualtında bulunan biyolojik organizmalar gürültü kaynağı olarak değerlendirilir ve sesi dağıtarak daha uzun mesafelere ulaşmasını engeller [5]. Sualtı ortamında ses hızı, üç ana temel nicelik olan tuzluluk, sıcaklık ve basınç parametrelerine bağlı olarak değişiklik göstermektedir. Bu temel niceliklerin aksine diğer fiziksel özelliklerin sualtı ortamında ses hızını etkilemediği belirlenmiştir [4]. 
Bu temel etkiler göz önünde bulundurularak literatürde sıcaklık, derinlik ve tuzluluk değerleri ile sualtı ortamında ses hızının hesaplanmasına yönelik farklı yöntemler sunulmuştur. Denklem (1) - Denklem (3)'de literatürde en fazla tercih edilen hesaplama yöntemleri sunulmuştur. Denklem (1)'de [6]'da Leroy tarafından tanımlanan ses hızı hesaplama yöntemi, Denklem (2)'de [7]'de Medwin tarafından tanımlanan ses hızı hesaplama yöntemi ve Denklem (3)'de [8]'de Mackenzie tarafından tanımlanan ses hızı hesaplama yöntemi için geliştirilen modeller gösterilmiştir.

Denklemlerde tanımlı $\mathrm{T}^{\circ} \mathrm{C}$ cinsinden sıcaklık değerini, D metre cinsinden derinlik değerini ve $\mathrm{S}$ pratik tuzluluk birimleri (p.s.u.- practical salinity units) cinsinden tuzluluk değerini göstermektedir. Denklem (1) Denklem (3)'den de görüleceği geliştirilen modeller ses hızının hesaplanmasında farklı sınır değerlerine sahiptirler.

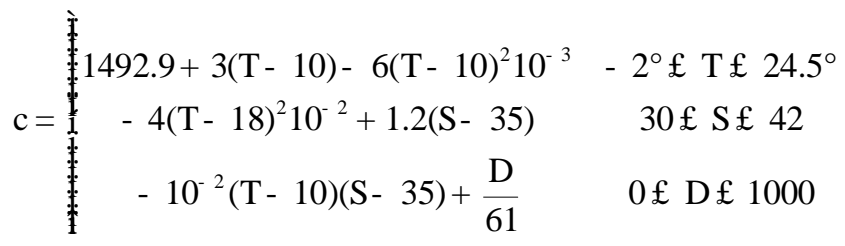

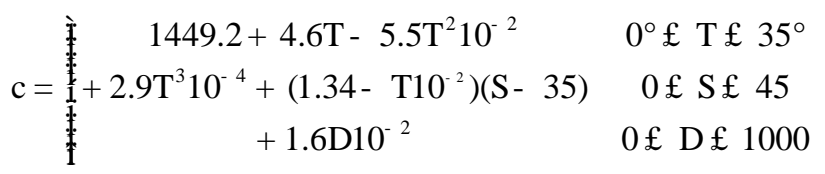

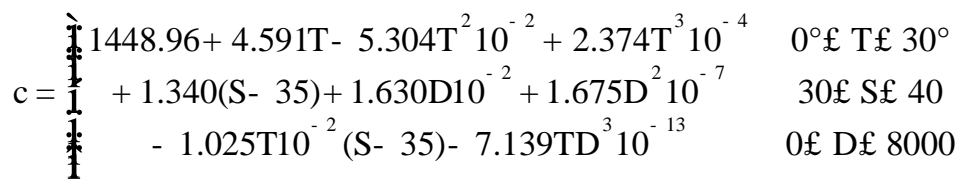

28 Kasım 2018 tarihinde Marmara denizinde CDT (Conductivity, Temperature, Pressure - İletkenlik, Sıcaklık, Basınç) ölçüm ucu [9] kullanılarak gerçekleştirilen ölçümlerde elde edilen derinliğe bağlı ses hızı profili ile birlikte ölçümlerde alınan derinliğe bağlı tuzluluk ve sıcaklık verileri Denklem (1) - Denklem (3)'de tanımlanan modellere uygulanmıştır. Şekil 1'de modeller sonucunda elde edilen ses hızı profilleri ile CDT prob ile elde edilen ses hızı profili gösterilmiştir. Şekil 1'de oluşturulan grafik için kullanılan verilerin her bir hesaplama yöntemine ait sınır değerleri ile uyumluluğu göz önünde bulundurulmuştur.

Şekil 2'de ses hızına bağlı olarak sualtı ortamında akustik sinyallerin davranışları gösterilmiştir. Ses hızının derinlikle beraber azalması durumu negatif eğim olarak ifade edilmekte ve genellikle bu durum yaz aylarında oluşmaktadır. Bu durumda kaynak-alıcı arası mesafe arttıkça akustik sinyallerde kırılmalar meydana gelmesi nedeni ile akustik sinyaller uzak mesafelere taşınamazlar (Şekil 2a). Ses hızının derinlikle beraber artması durumu pozitif eğim olarak ifade edilmekte ve genellikle bu durum kış aylarında oluşmaktadır (Şekil 2b). Ses hızının derinlikle beraber önce azalıp daha sonra artması durumunda ses kanalı oluşur ve akustik sinyaller bu kanal içerisinde hareket ederler (Şekil 2c). Şekil 2'den de görüleceği üzere akustik sinyaller ses hızının minimum olduğu bölgeye doğru hareket etmektedirler.

\section{A. Ortam Gürültüsü}

Ortam gürültüsü, gürültü seviyesi yapılacak sistemin bulunduğu noktada alınan ve sistemin gürültüsünden hariç olan gürültüdür. Sualtında meydana gelen ortam gürültüsü hem doğal hem de insan kaynaklı olmak üzere birçok kaynaktan meydana gelen gürültülerin toplamıdır. Birçok ortam gürültüsü kaynağı, Gauss istatistiklerine sahip sürekli frekans bantları oluşturur [10]. 


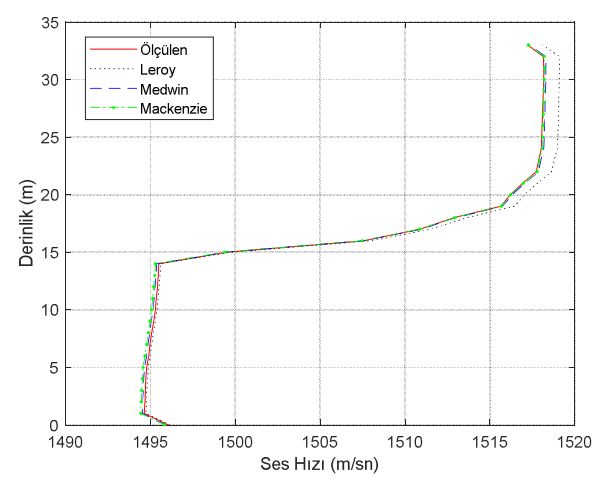

Şekil 1. Sualtı ortamında CDT prob ile farklı derinliklerde ses hızı ölçüm değerinin gösterimi ve literatürde önerilen hesaplama yöntemleri ile karşılaştırılması

(a)
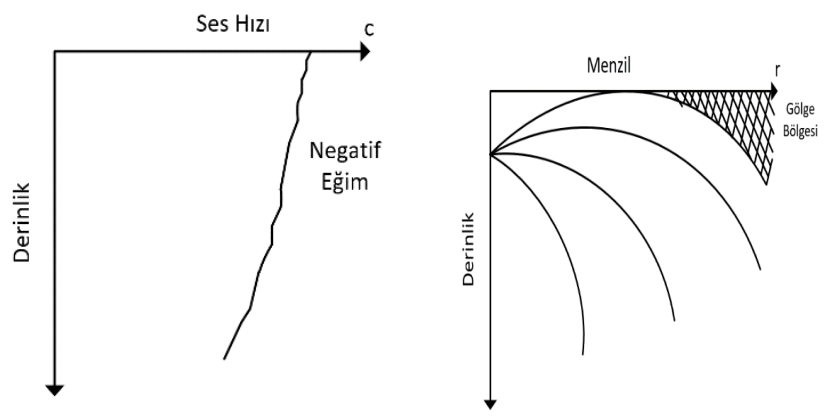

(b)
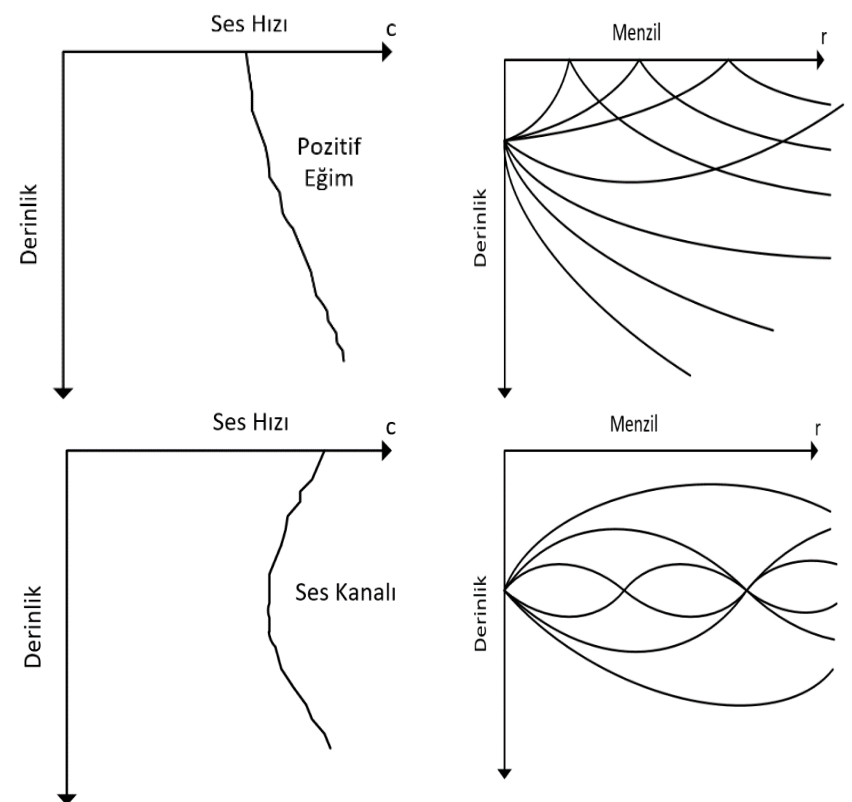

Şekil 2. Sualtı ortamında akustik sinyallerin ses hızına bağlı olarak hareketleri

Literatürde sualtı ortam gürültü seviyesinin modellenmesine ilişkin çeşitli çalışmalar mevcuttur. II. Dünya Savaşı sırasında yapılan ölçümler [11] ile deniz durumuna bağlı olarak her bir frekans binindeki gürültü seviyelerinin hesaplanmasına yönelik model ortaya konulmuştur. Bu modele alternatif olarak sıkılıkla kullanılan 
sualtı ortam modellerinin oluşturulmasına yönelik çalışmalar Wenz [12], Crouch [13] ve Urick [14] tarafından gerçekleştirilmiştir.

Bu çalışma kapsamında [15]'de önerilen doğal gürültü kaynaklarından termal gürültü, yüzey gürültüsü ve türbülans gürültüsüne ek olarak, insan kaynaklı gürültülerden gemi trafiği gürültüsü etkileri göz önünde bulundurularak ortam gürültüsü benzetimi işlemleri gerçekleştirilmiştir.

\section{B. Termal Gürültü̈}

Temel olarak su moleküllerinin rastgele hareket etmesi ile meydana gelen ve $50 \mathrm{KHz}$ 'den daha yüksek frekanslarda baskın olan termal gürültü [16], sualtı ortamında gerçekleştirilen akustik ölçümleri olumsuz yönde etkilemekte [17] ve oluşan gürültü seviyesi ölçülebilen ses seviyelerini ayarlamaktadır [16]. Sualtı ortamında oluşan termal gürültünün frekans karakteristiği Denklem (4)'de verilen formüle ile hesaplanır. Denklem (4)'de, f KHz cinsinden frekans değerini göstermektedir. Şekil 3'de termal gürültünün frekans karakteristiği verilmiştir.

$$
\mathrm{GS}_{\text {ter }}(\mathrm{f})=-15+20 \log (\mathrm{f})
$$

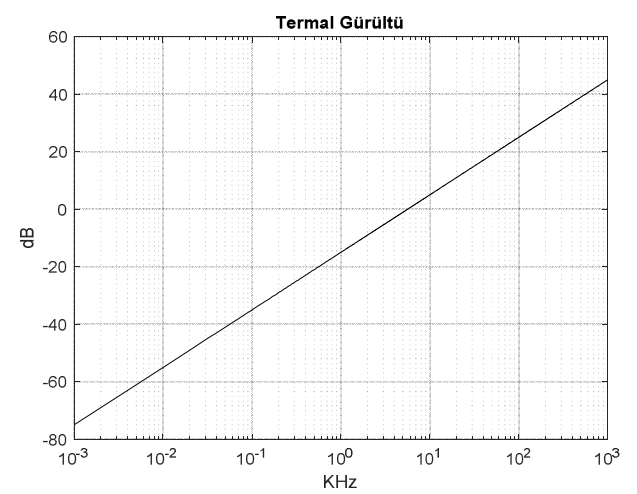

Şekil 3. Sualtı ortamında termal gürültü frekans karakteristiği

\section{Yüzey Gürültüsü}

Yüzey gürültüsü, rüzgâr hızına bağlı olarak farklı seviyelerde su yüzeyi üzerinde meydana gelen gürültüler olarak ifade edilmektedir. Sualtı ortamında oluşan yüzey gürültüsünün frekans karakteristiği Denklem (5)'de verilen formüle ile hesaplanır. Denklem (5)'de, f KHz cinsinden frekans değerini göstermektedir. w, m/sn cinsinden rüzgar hızını göstermektedir. Şekil 4'de'de farklı rüzgâr hızlarında oluşan yüzey gürültüsü frekans karakteristiği gösterilmiştir.

$$
\mathrm{GS}_{\mathrm{yuz}}(\mathrm{f})=50+7.5 \sqrt{\mathrm{w}}+20 \log (\mathrm{f})-40 \log (\mathrm{f}+0.4)
$$

\section{Gemi Trafiği Gürültüssü}

Yüzer taşıtlar tarafından sualtı ortamında yayılan akustik gürültü bileşenleri, makina hareketleri, düşürme dişlileri, akış gürültüsü, jeneratör ile tulumba ve fan gibi motorlardan çıkan gürültülerden oluşmakla birlikte, pervanenin yüksek hızlarda oluşturduğu kavitasyon gürültüsü de mevcuttur [18]. Deniz ortamına yayınlanan bu geniş bantlı akustik gürültü genelde $10 \mathrm{~Hz}$ ilâ $2 \mathrm{kHz}$ arasında gözlenir [19]. Sualtı ortamında oluşan gemi trafiği gürültüsünün frekans karakteristiği Denklem (6)'da verilen formüle ile hesaplanır. Denklem (6)'da, f KHz cinsinden frekans değerini, G gemi yoğunluğu faktörü değerini [0 1] aralığında ifade etmektedir.

$$
\mathrm{GS}_{\text {gemi }}(f)=40+20(\mathrm{G}-0.5)+26 \log (\mathrm{f})-60 \log (\mathrm{f}+0.03)
$$




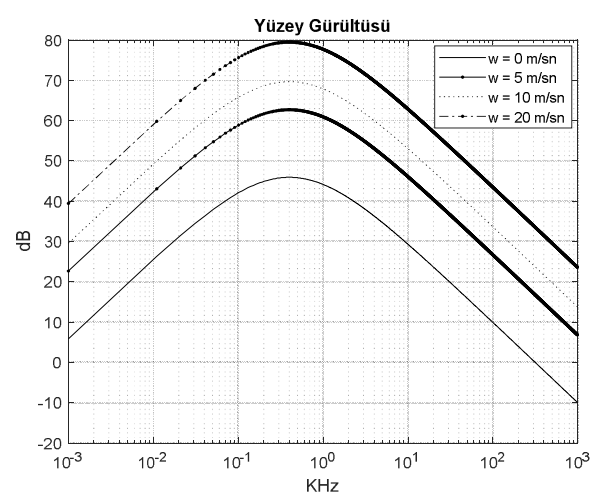

Şekil 4. Sualtı ortamında yüzey gürültüsü frekans karakteristiği

Şekil 5'de $\mathrm{G}=0, \mathrm{G}=0.5$ ve $\mathrm{G}=1$ gemi yoğunluğu faktörleri değerlerinde oluşan frekans karakteristiği gösterilmiştir.

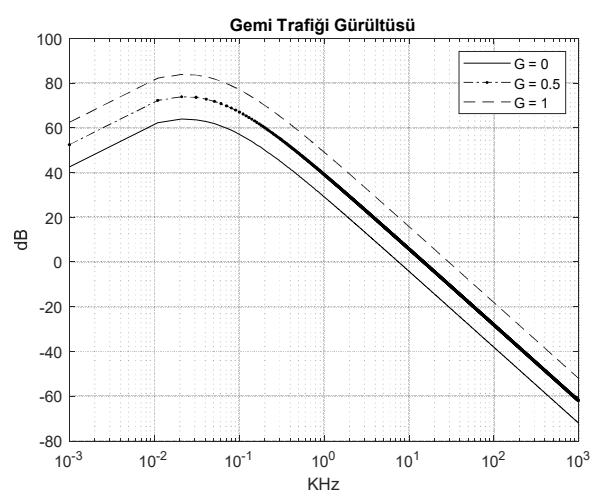

Şekil 5. Sualtı ortamında gemi trafiği gürültüsü frekans karakteristiği

\section{E. Türbülans Gürültüsü}

Sualtı ortamında türbülans gürültüsünün, etkisi özellikle düşük frekanslarda $(1 \mathrm{~Hz}-10 \mathrm{~Hz})$ çok yüksektir. Türbülans gürülttüsünün frekans karakteristĭgi Denklem (7)'de verilen formül ile hesaplanır. Denklem (7)'de, f $\mathrm{KHz}$ cinsinden frekans değerini göstermektedir. Şekil 6'da türbülans gürülttüsü karakteristiği gösterilmiştir.

$$
\mathrm{GS}_{\text {turb }}(\mathrm{f})=17-30 \log (\mathrm{f})
$$

\section{F. Toplam Ortam Gürültüsü}

Termal gürülttü, yüzey gürültüsü, gemi trafiği gürülttüsü ve türbülans gürültüsü etkileri göz önünde bulundurularak sualtı ortamına ait toplam gürültü Denklem (8)'deki gibi hesaplanmaktadır. Şekil 7'de farklı rüzgâr hızı ve gemi trafiği yoğunluğu değerlerinde ortam gürültüsü frekans karakteristikleri gösterilmiştir.

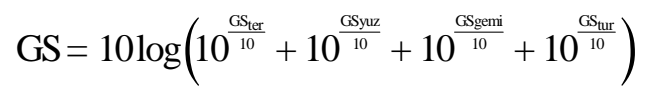




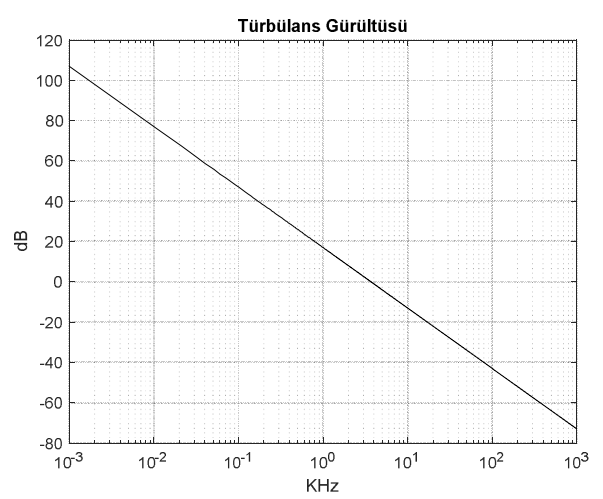

Şekil 6. Sualtı ortamında türbülans gürültüsü frekans karakteristiği

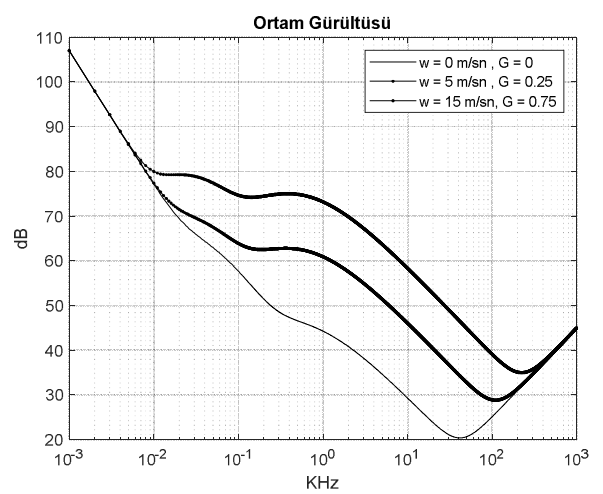

Şekil 7. Sualtı ortamında toplam gürültü frekans karakteristiği

\section{G. Iletim Kayıpları}

Sualtı ortamında iletim kayıpları yayılım ve dağılım kaynaklı olmak üzere iki şekilde meydana gelmektedir. Denklem (9)'dan da görüleceği üzere iletim kaybı (İK) mesafe (r), yayılma faktörü (K) ve frekans (f) değerlerine bağlı olarak değişkenlik göstermektedir ve yayılımdan dolayı meydana gelen kayıplar (YK) ile dağılımdan dolayı meydana gelen kayıpların (DK) toplamı olarak ifade edilir.

$$
\dot{\mathrm{I}} \mathrm{K}(\mathrm{r}, \mathrm{K}, \mathrm{f})=\mathrm{YK}(\mathrm{r}, \mathrm{K})+\mathrm{DK}(\mathrm{r}, \mathrm{f})
$$

Literatürde kaynaktan alıcıya kadar meydana gelen iletim kaybına yönelik farklı yaklaşımlar önerilmiş̧tir. Bunlardan en sıklıkla kullanılanı küresel yayılım modeli ile emilim kaybının birlikte hesaplanmasıdır (Denklem (10)) [20]. Denklem (10)' da İK iletim kaybını, metre cinsinden kaynak - alıcı arasındaki mesafeyi ve $\alpha$ emilim kaybını göstermektedir. Silindirik yayılım modeli kullanılarak elde edilen toplam iletim kaybı Denklem (11)'de pratik yayılım modeli kullanılarak elde edilen toplam iletim kaybı Denklem (12)'de gösterilmiştir. Bu çalışma kapsamında gerçekleştirilecek analizler kapsamında Denklem (10) - Denklem (12)'de tanımlanan yayılım modelleri kullanılacaktır.

$$
\begin{aligned}
& \dot{I} K(f)=20 \log _{10}^{\mathrm{r}}+\frac{\alpha(\mathrm{f}) \mathrm{r}}{10^{3}} \\
& \dot{\mathrm{IK}}(\mathrm{f})=10 \log _{10}^{\mathrm{r}}+\frac{\alpha(\mathrm{f}) \mathrm{r}}{10^{3}}
\end{aligned}
$$




$$
\dot{\mathrm{IK}}(\mathrm{f})=15 \log _{10}^{\mathrm{r}}+\frac{\alpha(\mathrm{f}) \mathrm{r}}{10^{3}}
$$

Denklem (13)'de Thorp [20] tarafından önerilen birkaç yüz Hz üzeri frekanslarda kullanılan daha basit ve özellikli emilim hesabı verilmiştir. Denklem (13)'de $\alpha$ emilim miktarını db/km cinsinden ve f frekans değerini $\mathrm{KHz}$ cinsinden tanımlanmaktadır [21].

$$
\alpha=\frac{0.1 \mathrm{f}^{2}}{1+\mathrm{f}^{2}}+\frac{40 \mathrm{f}^{2}}{4100+\mathrm{f}^{2}}+2.75 \times 10^{-4} \mathrm{f}^{2}+0.003
$$

Birkaç yüz Hz aşağısı frekanslar için ise Denklem (14) ile verilen eşitlik kullanılabilir [21].

$$
\alpha=0.002+0.11 \frac{\mathrm{f}^{2}}{1+\mathrm{f}^{2}}+0.011 \mathrm{f}^{2}
$$

Şekil 8'de Denklem (13) ve Denklem (14)'de verilen hesaplama yöntemi kullanılarak frekansa bağlı olarak emilim miktarları gösterilmiştir. Şekil 8'den de görüleceği üzere düşük frekanslarda emilim miktarı neredeyse yok denecek kadar az iken yüksek frekanslara çıkıldıkça emilim miktarı yüksek seviyelere çıkmaktadır. Bu nedenle sualtı ortamında yüksek frekansların kullanımı çok tercih edilememektedir.

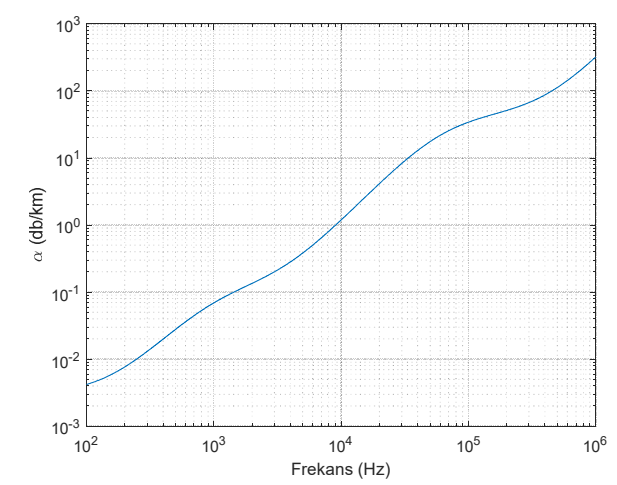

Şekil 8. Formül (13)'de verilen hesaplama yöntemine göre frekansa bağlı olarak emilim miktarlarının değişimi

\section{H. Çok Yolluluk Etkisi}

Sualtı ortamında kaynaktan yayılan sinyaller algılayıcıda, direk yolla birlikte ulaşan sinyalin yüzeyden ve dipten yansımaların etkisi ile algılayıcıya gecikmeli olarak ulaşan sinyaller ile toplamı şeklinde algılanmaktadır. Bu etki göz önünde bulundurularak sinyallerin oluşturmasına yönelik çalışmalar yapılmıştır.

Şekil 9'da kaynaktan yayılan sinyalin 3 yoldan algılayıcıya ulaşma şekli gösterilmiştir. Çok yolluluk etkisi ile meydana gelecek gecikmeler yüzey ile dip arasındaki derinlik $(\mathrm{H})$, kaynak ile yüzey arasındaki derinlik $\left(\mathrm{h}_{\mathrm{K}}\right)$, alıcı ile yüzey arasındaki derinlik $\left(\mathrm{h}_{\mathrm{A}}\right)$, kaynak ile alıcı arasındaki yatay mesafeye $\left(\mathrm{R}_{\mathrm{KA}}\right)$ bağlı olarak hesaplanmaktadır. Gecikmelerin sebep olacağı kayıplar ile birlikte dipten ve yüzeyden yansımalara ilişkin zayıflamalar göz önünde bulundurularak algılayıcıda alınan sinyalin genlik seviyeleri hesaplanmaktadır. 


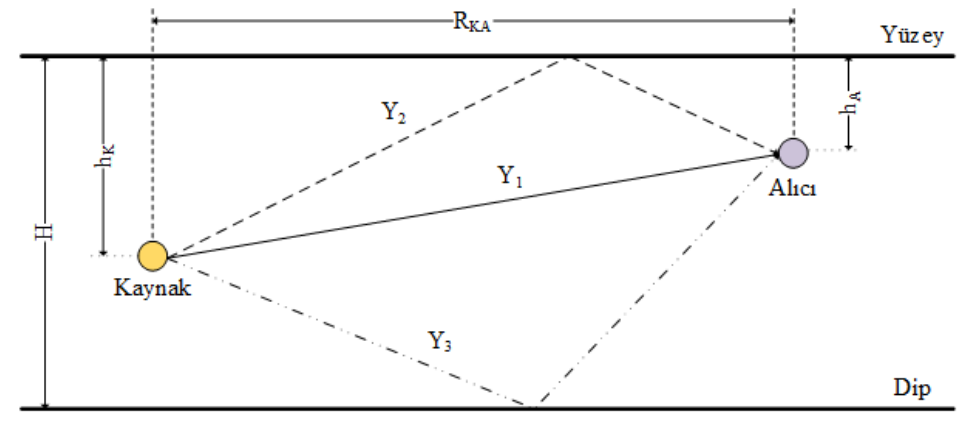

Şekil 9. Kaynaktan algılayıcıya çok yolluluk etkisi

Şekil 9'da gösterilen $Y_{1}$ yolu için sinyalin algılayıcıya ulaşıncaya kadar aldığı yol denklem (15), $Y_{2}$ yolu için sinyalin algılayıcıya ulaşıncaya kadar aldığı yol hesabı denklem (16) ve $Y_{3}$ yolu için sinyalin algılayıcıya ulaşıncaya kadar aldığı yol hesabı denklem (17)'deki gibi hesaplanmaktadır.

$$
\begin{aligned}
& \mathrm{X}_{\mathrm{Y}_{1}}=\sqrt{\left|\mathrm{h}_{\mathrm{K}}-\mathrm{h}_{\mathrm{A}}\right|^{2}+\mathrm{R}_{\mathrm{KA}}^{2}} \\
& \mathrm{X}_{\mathrm{Y}_{2}}=\sqrt{\left(\mathrm{h}_{\mathrm{K}}+\mathrm{h}_{\mathrm{A}}\right)^{2}+\mathrm{R}_{\mathrm{KA}}^{2}} \\
& \mathrm{X}_{\mathrm{Y}_{3}}=\sqrt{\left(2 \mathrm{H}-\mathrm{h}_{\mathrm{K}}-\mathrm{h}_{\mathrm{A}}\right)^{2}+\mathrm{R}_{\mathrm{KA}}^{2}}
\end{aligned}
$$

Algılayıcıya ulaşan yollara ait uzaklıkların hesaplanmasından sonra bu uzaklıklarda meydana gelecek yol kayıpları hesaplanmaktadır. Yol kayıplarına dipten ve yüzeyden yansımalarda meydana gelen kayıplarda eklenerek algılayıcıda sinyalin uğradığg yol kaybı hesaplanır (Denklem (18)). Denklem (18)'de İK ${ }_{\mathrm{DP}} \mathrm{dB}$ cinsinden dipten yansıma kaybını, $\mathrm{N}$ dipten kaç yansıma olduğunu, $\mathrm{I}_{\mathrm{YZ}} \mathrm{dB}$ cinsinden yüzeyden yansıma kaybını ve $\mathrm{M}$ yüzeyden kaç yansıma olduğunu göstermektedir.

$$
\dot{\mathrm{I}} \mathrm{K}_{\mathrm{T}}=\dot{\mathrm{I}} \mathrm{K}_{\mathrm{YK}}+\mathrm{N} \cdot \mathrm{I} \mathrm{K}_{\mathrm{DP}}+\mathrm{M} \cdot \dot{\mathrm{IK}} \mathrm{YZ}_{\mathrm{Y}}
$$

\section{BANT GENIŞLİĞİ, KAPASİTE VE İLETIM GÜCÜNÜN HESAPLANMASI}

Bu bölümde, Bölüm 2'de tanımlanan modeller ve yaklaşımlar kullanılarak analizler gerçekleştirilmiştir. Gerçekleştirilen analizler hem vericinin hem de alıcının her aktarım için kanal aktarım fonksiyonunun tam olarak bilindiği ve kanal fonksiyonunun her aktarım sırasında değişmediği varsayımı ile yapılmıştır.

\section{A. Toplam Sinyal Zayıflaması Ve Sinyal Gürültü Oranı}

Kaynak tarafından $\mathrm{f}$ frekansında ve $\mathrm{P}$ gücünde bir ton sinyalinin frekans ve kaynak alıcı arasındaki mesafeye (1) bağlı olarak meydana gelen zayıflama ( İK $(1, f)$ ) ve alıcının bulunduğu konumda f frekansında bulunan gürültü güç izge yoğunluğu ile sinyal gürültü oranı (SNR) hesaplanabilir. Farklı yol kayıpları ve alıcı yönlülük indeksi parametrelerinin hesaba katılmadığg dar bant SNR seviyesi Denklem (19)'daki gibi hesaplanır.

$$
\operatorname{SNR}(1, f)=K S-\dot{I} K(1, f)-G S(f)-10 \log B
$$

Denklem (19)'da KS dB cinsinden kaynak seviyesini, İK(l,f) dB cinsinden kaynak-alıcı arasındaki mesafe ve kaynak tarafından iletilen sinyalin frekansına bağlı olarak iletim kaybını, GS(f) ise dB cinsinden 
kaynak tarafından yayılan sinyal frekansında alıcıdaki ortam gürültüsünü, B ise alıcı bant genişliğini $\mathrm{Hz}$ değerinden ifade etmektedir.

Şekil 10'da kaynak alıcı arasındaki mesafenin 5 km, 10 km, 50 km ve 100 km olduğu durumlarda dar bant SNR'ın frekansa bağımlılığı silindirik (Şekil 10a), pratik (Şekil 10b) ve küresel (Şekil 10c) yayılım modelleri kullanılarak gösterilmiştir. Ortam gürültüsü için gemi yoğunluğu değeri 0.5 ve rüzgâr hızı $0 \mathrm{~m} / \mathrm{sn}$ olarak alınmıştır. Şekil 10'dan da görüleceği üzere dar bant SNR'ın frekansa bağımlığı karakteristik olarak yayılım modelinden bağımsız olmasına rağmen seviyelerin yayılım modeline bağlı olduğu gözlenmiştir.

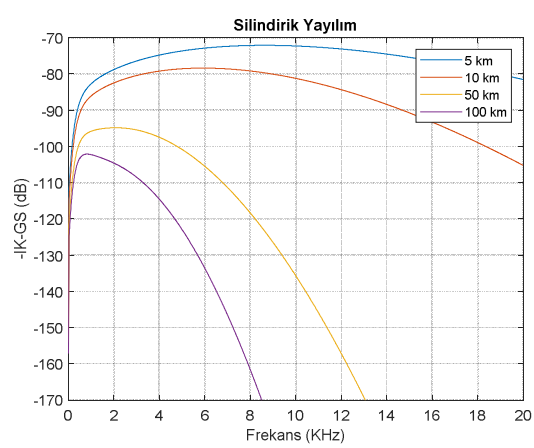

(a)

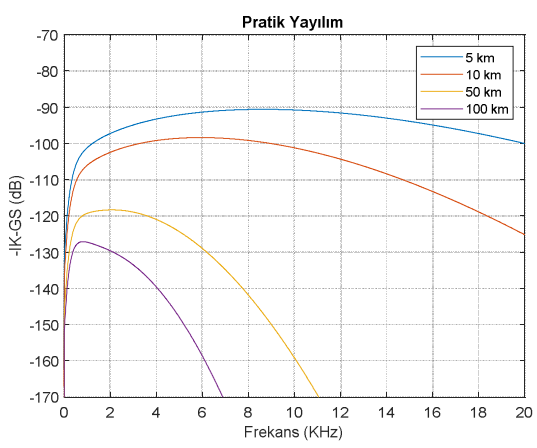

(b)

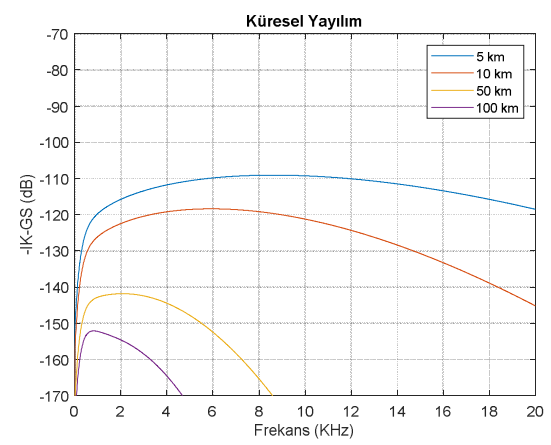

(c)

Şekil 10. Dar bant SNR'ın frekansa bağımlılığı

Şekil 11'de mesafeye bağlı olarak en iyi frekanslar silindirik, pratik ve küresel yayılım modellerine göre gösterilmiştir. Şekil 11'den de görüleceği üzere en iyi frekans değerinin yayılım modelinden bağımsız olduğu görülmektedir. En iyi frekans değerleri elde edilen çıktı değerleri içerisinden maksimum değerin bulunduğu noktalara denk gelen frekans değerleri seçilmiştir.

\section{B. Bant Genişliği ve Kapasite}

Kaynak seviyesi, bant genişliği içerisindeki frekansları kapsayan toplam ortam gürültü seviyesinin, frekans ve mesafeye bağlı ters iletim kaybının toplamına bölümü ile her bir frekans değeri için gerekli kaynak seviyesi bulunur. Bulunan bu değer bant genişliği ile çarpıldıktan sonra $0 \mathrm{~dB}$ SNR seviyesi için gerekli kaynak seviyesi bulunur. Bu değerin üzerine kaynaktan alıcıya ulaşan sinyalin asgari olarak istenen SNR seviyesi eklendiğinde kaynak seviyesi elde edilmiş olunur (Denklem (20)). 


$$
\mathrm{KS}(\mathrm{l})=\operatorname{SNR}_{0} \mathrm{~B}(\mathrm{l}) \frac{\int_{\mathrm{B}(1)} \mathrm{GS}(\mathrm{f}) \mathrm{df}}{\int_{B(1)} \dot{\mathrm{I}} \mathrm{K}^{-1}(1, \mathrm{f}) \mathrm{df}}
$$

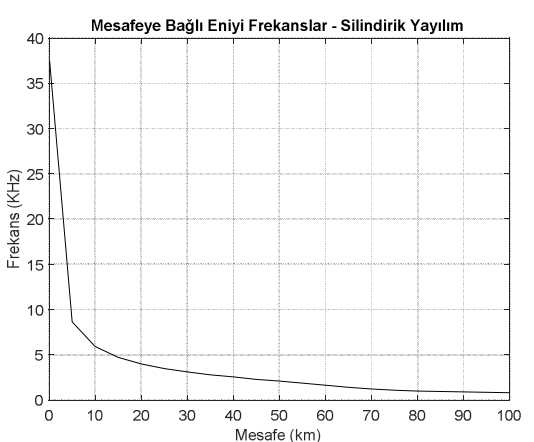

(a)

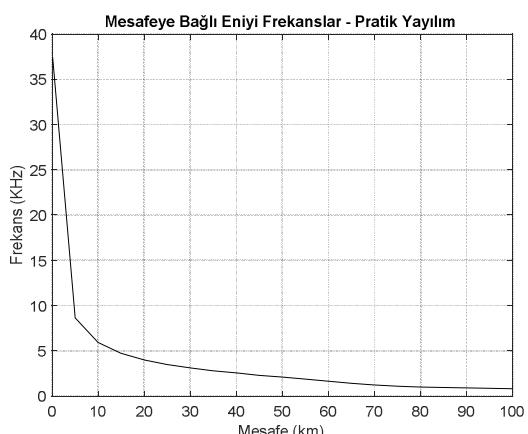

(b)

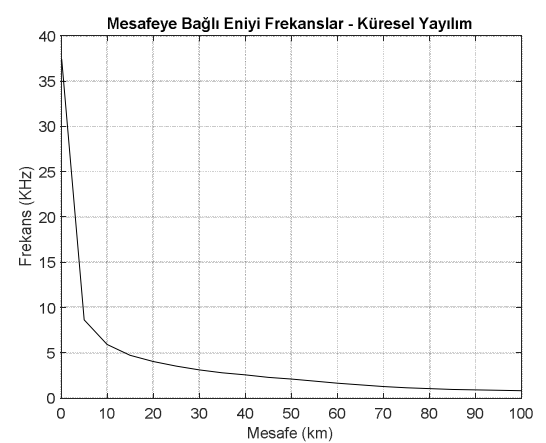

(c)

Şekil 11. Mesafeye bağımlı en iyi frekanslar

Denklem (20)'de KS kaynak seviyesini, $\mathrm{SNR}_{0}$ alıcıda gerekli sinyal gürültü oranını, GS ortam gürültü seviyesini, İK iletim kaybını, B bant genişliğini, 1 kaynak alıcı arasındaki mesafeyi ve $f$ frekans değerini göstermektedir.

Bant genişliği belirleme işlemleri için $3 \mathrm{~dB}$ bant genişliği yöntemi kullanılmıştır (Şekil 12). Şekil 12'den de görüleceği üzere $3 \mathrm{~dB}$ bant genişliği $\mathrm{f}_{0}$ merkez frekansından düşük frekanslarda seviyenin $3 \mathrm{~dB}$ azaldığı nokta $f_{1}$, ve $f_{0}$ merkez frekansından yüksek frekanslarda seviyenin $3 \mathrm{~dB}$ azaldığ nokta $\mathrm{f}_{2}$ arasında kalan frekans $\left(\mathrm{f}_{2}-\mathrm{f}_{1}\right)$ bölgesi olarak tanımlanır.

Çalışma kapsamında bant genişliği hesaplama işlemleri dar bant SNR'ın frekansa bağımlılığı işlemleri sonucunda elde edilen çıktılar kullanılarak gerçekleştirilmiştir. Merkez frekans olarak maksimum değerin bulunduğu frekans değeri seçilmiştir. Alt ve üst frekanslar için ise, maksimum değerinin bulunduğu frekans değerinin aşağısı ve yukarısında $3 \mathrm{~dB}$ 'lik azalmalar tespit edilmektedir.

Kapasite bir kanalın performansının ölçülmesinde kullanılan ilk argümanlardan biridir. Gürültünün Gaussian olduğu ve kanalın belirli bir süre için zamanla değişmez olduğu varsayıldığında, toplam bant genişliğinin birçok dar alt banda bölünmesi ve bireysel kapasitelerin toplanmasıyla kapasite elde edilebilir. Bir haberleşme kanalının iletim kapasitesi işaretin gücü, bant genişliği ve bant genişliğinin bulunduğu frekans bölgesindeki ortam gürültüsü, kaynak-alıcı arasındaki mesafeye bağlı olarak hesaplanabilir (Denklem (21). 


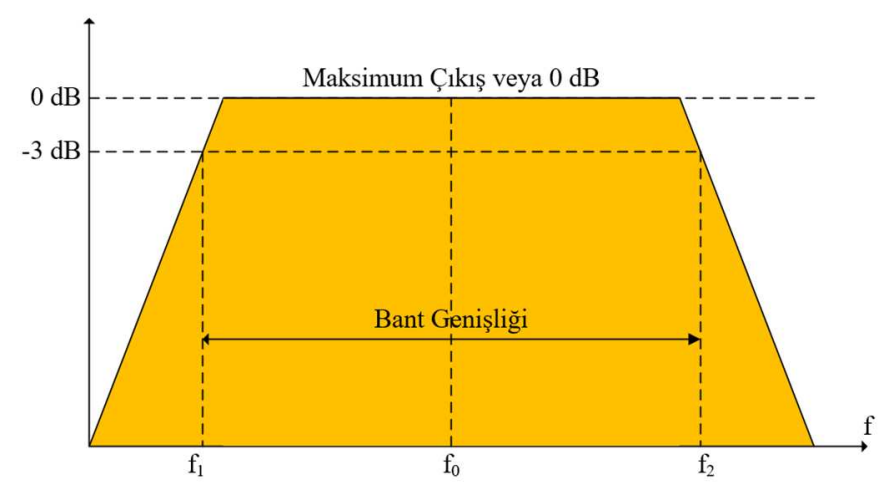

Şekil 12. $3 \mathrm{~dB}$ bant genişliği

$$
\mathrm{C}(\mathrm{l})=\int_{\mathrm{B}(\mathrm{l})} \log _{2}\left(1+\frac{\frac{\mathrm{KS}(\mathrm{l})}{\mathrm{B}(\mathrm{l})}}{\mathrm{IK}(\mathrm{l}, \mathrm{f}) \mathrm{GS}(\mathrm{f})}\right)
$$

Denklem (21)'de C kanal kapasitesi değerini her bir saniyede iletilen bit sayısı (bit per second - bps) olarak ifade etmektedir. KS kaynak seviyesi değerini, İK iletim kaybını, GS ortam gürültü seviyesini göstermektedir. B Hz biriminde bant genişliğini göstermektedir. 1 metre cinsinden kaynak-alıcı arasındaki mesafeyi, f $\mathrm{Hz}$ cinsinden frekans değerini göstermektedir.

Alıcıda gerekli olan SNR değeri $20 \mathrm{~dB}$ seçilerek ve silindirik yayılım modeli kullanılarak elde edilen bant genişliği ve kapasite değerleri Şekil 13a'da, iletim gücü ise Şekil 13b'de gösterilmiştir.

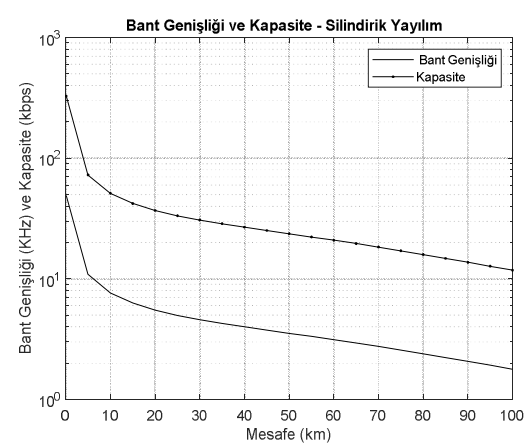

(a)

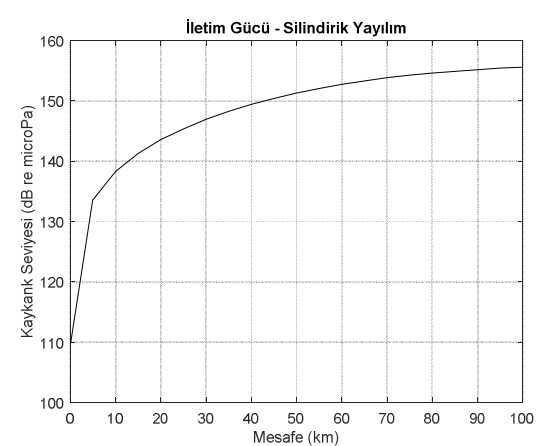

(b)

Şekil 13. $\mathrm{SNR}_{0}=20 \mathrm{~dB}$ seçilerek ve silindirik yayılım modeli kullanılarak elde edilen a) mesafeye bağlı bant genişliği ve kapasite, b) mesafeye bağlı iletim gücü

Şekil 14a ve Şekil 15a'da ise alıcıda gerekli olan SNR değeri 20 dB seçilerek sırasıyla pratik ve küresel yayılım modelleri kullanılarak elde edilen bant genişlikleri ve kapasite değerleri, Şekil 14b ve Şekil 15b'de ise iletim güçleri gösterilmiştir. Şekil 13a, Şekil 14a ve Şekil 15a'dan da görüleceği üzere yayımlım modelinin kapasite ve bant genişliği üzerine etkisi olmamaktadır. Şekil 13b, Şekil 14b ve Şekil 15b'den de görüleceği üzere yayılım modeli kaynak iletim gücünü direkt olarak etkilemektedir. 


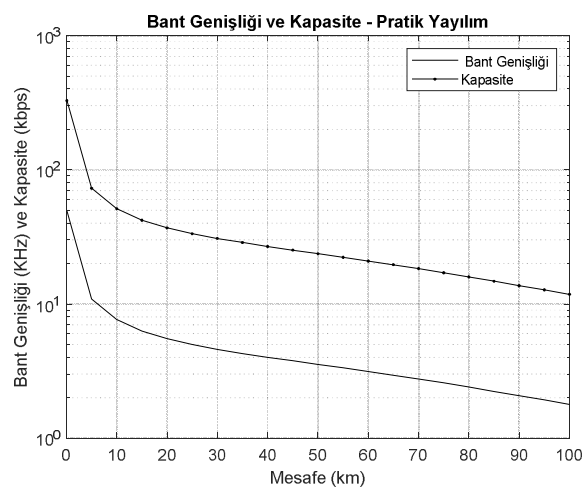

(a)

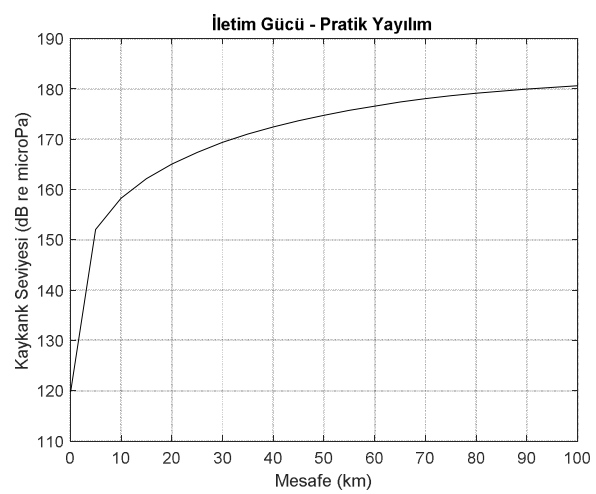

(b)

Şekil 14. $\mathrm{SNR}_{0}=20 \mathrm{~dB}$ seçilerek ve pratik yayılım modeli kullanılarak elde edilen a) mesafeye bağlı bant genişliği ve kapasite, b) mesafeye bağlı iletim gücü

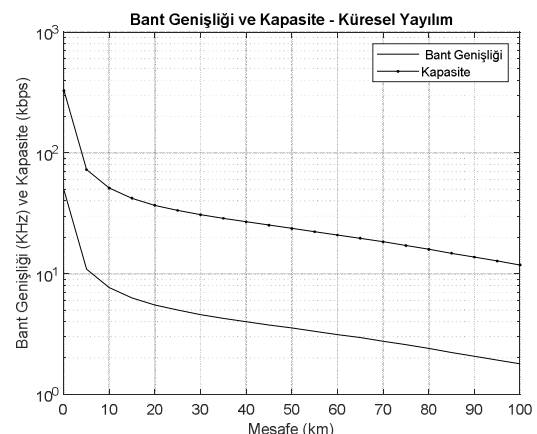

(a)

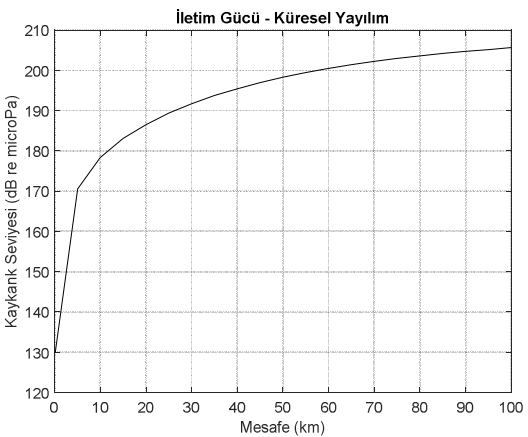

(b)

Şekil 15. $\mathrm{SNR}_{0}=20 \mathrm{~dB}$ seçilerek ve küresel yayılım modeli kullanılarak elde edilen a) mesafeye bağlı bant genişliği ve kapasite, b) mesafeye bağlı iletim gücü

Şekil 16'da kaynak alıcı arasında zayıflama olarak pratik yayılım modeli kullanıldığında ve emilimden dolayı meydana gelen yol kayıplarına ek olarak dip/yüzey zayıflamalarının olmadığı hesaba katılarak, kaynak alıcı arasında 5 yol, 25 yol ve 100 yol olduğu durumlarda farklı kaynak alıcı arası mesafeler için bant genişlikleri ve kapasiteleri gösterilmiştir. Şekil 16'dan da görüleceği üzere yol sayısı arttıkça bant genişliği ve kapasite eğrilerinde bozulmalar meydana gelmektedir.

Şekil 17'de kaynak alıcı arasında zayıflama olarak pratik yayılım modeli kullanıldığında ve emilimden dolayı meydana gelen yol kayıplarına ek olarak, dip/yüzey zayıflamalarının 1 dB olduğu hesaba katılarak, kaynak alıcı arasında 5 yol, 25 yol ve 100 yol olduğu durumlarda, farklı kaynak alıcı arası mesafeler için bant genişlikleri ve kapasiteleri gösterilmiştir. Şekil 17'den de görüleceği üzere bu durum için yol sayısı arttıkça bant genişliği ve kapasite eğrilerinde bozulmalar meydana gelmemektedir. 


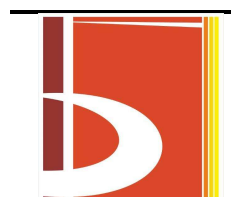

BŞEÜ Fen Bilimleri Dergisi

BSEU Journal of Science

7(1), 404-420, 2020

DOI: 10.35193/bseufbd.706560

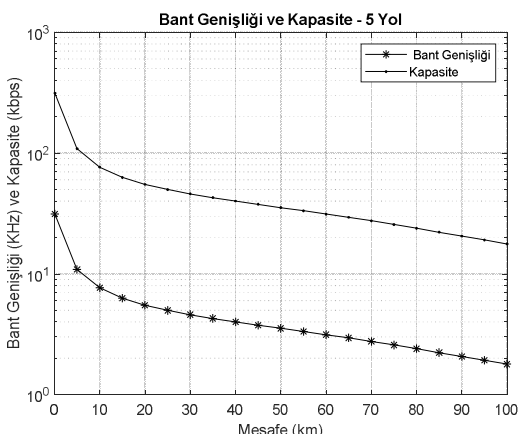

(a)

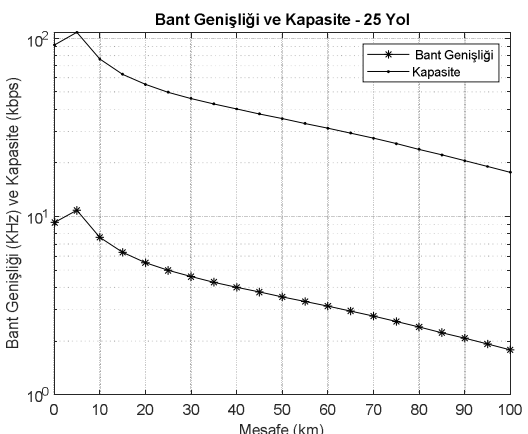

(b)

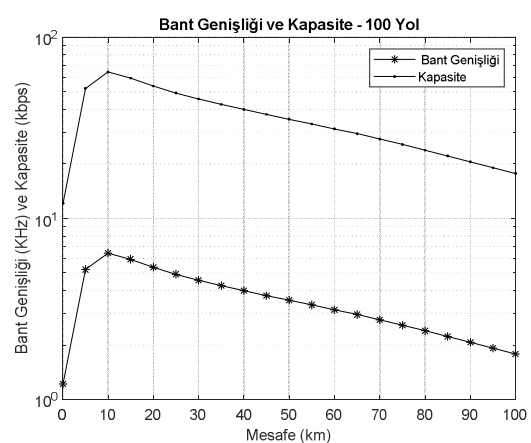

(c)

Şekil 16. Dip ve yüzey zayıflaması olmadığı durumda mesafeye bağlı kapasite ve bant genişliği

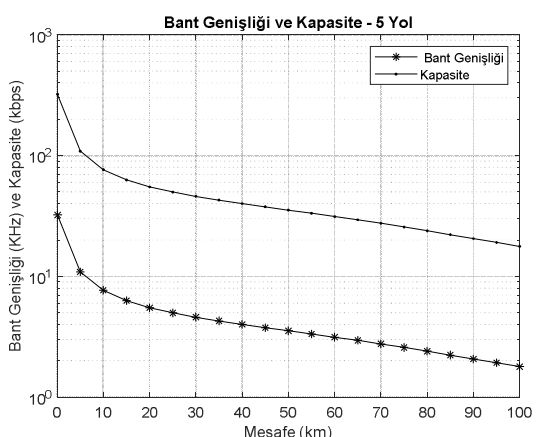

(a)

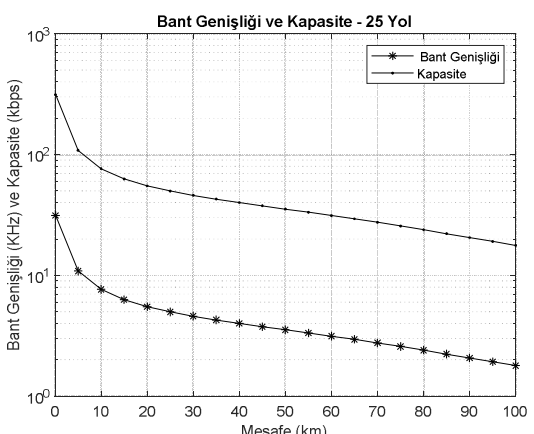

(b)

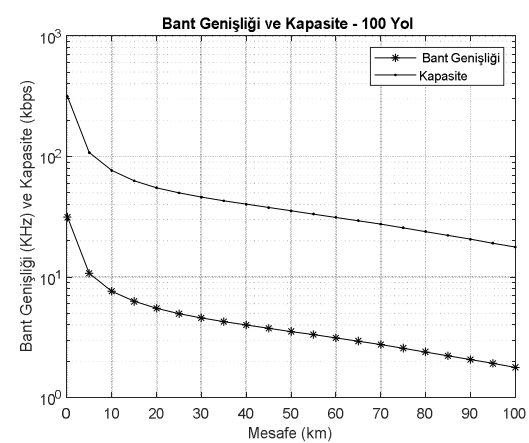

(c)

Şekil 17. Dip ve yüzey zayıflaması $1 \mathrm{~dB}$ olduğu durumda mesafeye bağlı kapasite ve bant genişliği 


\section{SONUÇLAR}

Sualtı ortamında haberleşme sisteminde kaynaktan yayılan sinyaller, kaynak-alıcı arasındaki mesafeye bağlı olarak yayılım kaybına ve olarak emilim kaybına uğradıktan sonra alıcıda alınır. Bu nedenle haberleşmenin gerçekleştirileceği mesafe ve iletilecek bilginin boyutu haberleşme sistemin kullanacağı bant genişliğini, kapasitesini ve kaynak gücünü doğrudan etkilemektedir.

Sualtı ortamında kış aylarında yaz aylarına göre daha uzak mesafelerde haberleşme gerçekleştirilebilmektedir (Şekil 2). Haberleşme sisteminin performansı sualtında meydana gelen anlık değişimlerden (sıcaklık, tuzluluk, vb) doğrudan etkilenmektedir. Literatürde sunulan birçok çalışmada sualtı ortamında kaynak alıcı arasında oluşacak kanal modeli kestirimlerinde özellikle emilim kaybı hesapları frekansa bağlı olarak gerçekleştirilmiştir.

Çalışma kapsamında literatürde önerilen frekansa bağımlı emilim kaybı fonksiyonu kullanılarak farklı mesafeler için öncelikle dar bant SNR'ın frekans bağlılığı hesaplama işlemleri silindirik, pratik ve küresel yayılım modelleri için gerçekleştirilmiştir (Şekil 10). Elde edilen sonuçlarda yayılım modelinin SNR seviyesine doğrudan etkilediği görülmüş fakat mesafeye bağlı olarak davranışı etkilemediği görülmüştür. Analizlerin devamında mesafeye bağlı olarak en iyi frekansların hesaplama işlemleri üç yayılım modeli içinde gerçekleştirilmiştir (Şekil 12). Elde edilen sonuçlar yayılım modelinin en iyi frekans değerine etkisinin olmadığını göstermiştir.

Bant genişliği, kapasite ve iletim gücü hesaplarında farklı SNR seviyelerinde 3 yayılım modeli kullanılmıştır. Bant genişliğinin SNR seviyesinden ve yayılım modelinden bağımsız (Şekil 13a, Şekil 14a ve Şekil 15a) olduğu ve tüm analizler için aynı değeri gösterdiği gözlemlenmiştir. İletim gücü değeri ise yayılım modelinden doğrudan etkilenmektedir (Şekil 13b, Şekil 14b ve Şekil 15b).

Çok yolluluğun bant genişliği, kapasite ve iletim gücü üzerine etkisi analizlerinde, algılayıcıda alınan yansıyan sinyal sayısı arttıkça yakın mesafelerde hesaplamalarda bozulmalar meydana gelmektedir. Benzer şekilde yüzeyden ve dipten yansıma kayıplarının seviyelerinin analizleri doğrudan etkilediği gözlemlenmiştir (Şekil 15 ve Şekil 16).

\section{KAYNAKLAR}

[1] Dola, H., Bloma, K., Colina, M., Priora, M. (2017). Characterizing the Underwater Acoustic Communications Channel in Shallow Estuaries and its Application to the Development of a Flexible Wideband Modulation. 4th Underwater Acoustics Conference and Exhibition, 3-8 Eylül, Island of Skiathos, 933-940.

[2] Stojanovic, M., Preisig, J. (2009). Underwater Acoustic Communication Channels: Propagation Models and Statistical Characterization. IEEE Commun. Mag. 47(1), 84-89.

[3] Hayward, T. J., Yang, T. C. (2004). Underwater Acoustic Communication Channel Capacity: A Simulation Study. AIP Conference Proceedings, 19-30 Temmuz, Mexico City, 114-121.

[4] Urick, R. J. (1983). Principles of Underwater Sound. 3rd Ed. McGraw Hill Book Co., New York, 423.

[5] Etter, P. C. (2018). Underwater Acoustic Modeling and Simulation. CRC press, Florida, 638.

[6] Leroy, C. C. (1969). Development of Simple Equations for Accurate and More Realistic Calculation of the Speed of Sound in Seawater. J. Acoust. Soc. Am., 46(1B), 216-226.

[7] Medwin, H. (1975). Speed of Sound in Water: A Simple Equation for Realistic Parameters. J. Acoust. Soc. Am., 58(6), 1318-1319.

[8] Mackenzie, K. V. (1981). Nine $\square$ Term Equation for Sound Speed in the Oceans. J. Acoust. Soc. Am., 70(3), 807-812. 
[9] RBR. (2020). https://rbr-global.com/products/standard-loggers/rbrduo-ct, (18.03.2020).

[10] Richard, P. H. (2010). Underwater Acoustics: Analysis, Design, and Performance of Sonar. John Wiley and Sons, West Sussex, 366.

[11] Knudsen, V. O., Alford, R. S., and Emiling, J. W. (1944). Survey of Underwater Sound, Report 3. Ambient Noise. NRDC 1848.

[12] Wenz, G. M. (1962). Acoustic Ambient Noise in the Ocean: Spectra and Sources. J. Acoust. Soc. Am., 34(12), 1936-1956.

[13] Crouch, W. W. (1972). Ambient Noise in the Sea. http://users.ece.utexas.edu/ ling/1A_US1.pdf, Naval Underwater Systems Center, (18.03.2020).

[14] Urick, R. J. (1982). Sound Propagation in the Sea. Peninsula Publishing, California, 226.

[15] Coates, R. (1989). Underwater Acoustic Systems, Wiley, New York, 188.

[16] What are common underwater sounds. (2018). https://dosits.org/science/sounds-in-the-sea/what-arecommon-underwater-sounds/, (18.03.2020).

[17] Readhead, M. L. (2014). Is Underwater Thermal Noise Useful?. Inter-Noise and Noise-Con Congress and Conference Proceedings, 16-19 Kasim, Melbourne, 4978-4983.

[18] Özen, S., Öner, M., Çavuşlu, M. A., İlgüy, A. C., Tatar, Ö., Başaran, Y. H. (2013). Simulation and Estimation of Underwater Acoustical Tonals Emanating From Naval Platforms. 21st Signal Processing and Communications Applications Conference (SIU), 24-26 Nisan, Girne, Kıbrıs, 1-4.

[19] Özen, S., Çavuslu, M. A., Basaran, Y. H., Öner, M., Tatar, Ö. (2012). Deniz Platformlarının ve Sualtı Ortamı Akustik Sinyallerinin Benzetimi. 20st Signal Processing and Communications Applications Conference (SIU), 18-20 Nisan, Muğla, 1-4.

[20] Thorp, W. H. (1967). Analytic Description of the Low $\square$ Frequency Attenuation Coefficient. J. Acoust. Soc. Am., 42:1, 270.

[21] Stojanovic M., On the Relationship Between Capacity and Distance in an Underwater Acoustic Communication Channel, Proceedings of the First Workshop on Underwater Networks, WUWNET 2006; Los Angeles, CA, USA. 25 September 2007 